\title{
Rating requirements of a unified power quality conditioner (UPQC) for voltage ride through capability enhancement
}

\author{
N. G. Jayanti \\ Technological University Dublin \\ Malabika Basu \\ Technological University Dublin, mbasu@tudublin.ie \\ Michael Conlon \\ Technological University Dublin, michael.conlon@tudublin.ie
}

See next page for additional authors

Follow this and additional works at: https://arrow.tudublin.ie/engscheleart

Part of the Electrical and Computer Engineering Commons

\section{Recommended Citation \\ Jayanti, N. G. :Rating requirements of a unified power quality conditioner (UPQC) for voltage ride through capability enhancement. 3rd IET International Conference on Power Electronics, Machines and Drives, Dublin, Ireland, 2006, pp.632-636. doi:10.21427/86z4-av23}

This Conference Paper is brought to you for free and open access by the School of Electrical and Electronic Engineering at ARROW@TU Dublin. It has been accepted for inclusion in Conference papers by an authorized administrator of ARROW@TU Dublin. For more information, please contact arrow.admin@tudublin.ie, aisling.coyne@tudublin.ie,gerard.connolly@tudublin.ie. Funder: Enterprise Ireland Technology Commercialisation Fund.

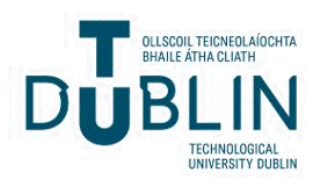




\section{Authors}

N. G. Jayanti, Malabika Basu, Michael Conlon, and Kevin Gaughan 


\title{
Rating Requirements of a Unified Power Quality Conditioner (UPQC) for Voltage Ride Through Capability Enhancement
}

\author{
N. G. Jayanti, Malabika Basu, Michael F. Conlon, Kevin Gaughan \\ School of Control Systems and Electrical Engineering \\ Dublin Institute of Technology, Kevin Street, Dublin 8, Ireland
}

Keywords: Power Quality, Voltage Sag, Renewable Generation, UPQC

\begin{abstract}
The problem of voltage ride through capability of fixed speed wind generation as a result of voltage sags is examined by means of a simulation study. The role of a Unified Power Quality Conditioner (UPQC), which provides both shunt and series compensation, in enhancing the ride through capability is investigated under both full and partial voltage restoration. Results of a study to identify the minimum rating requirements to ensure stability are presented.
\end{abstract}

\section{Introduction}

To comply with the environmental regulations and to cater to increasing energy demand, there has been rapid growth in installed wind capacity in Ireland. Currently, $341 \mathrm{MW}$ of wind energy is operational across 40 separate wind farm projects. Many other wind farm projects are in various stages of construction which will add another $575 \mathrm{MW}$ to the existing installed wind capacity in next 12-14 months [1]. In addition, an excess over 2,000 MW of formal connection applications have been received by ESB National Grid. Due to increased penetration of wind energy into the power system, the grid codes which were originally developed for synchronous generators had to be revised. In Ireland, new grid codes have been effective from May 2005. A critical issue for wind generation under the grid code is the requirement that wind generators (WG) should have the ability to stay connected to the grid after a fault, that is the generators should have fault ride-through capabilities. In the past, during a network fault or a sudden drop in frequency, wind turbines were tripped off the system. This tripping can cause serious problems for the system security and can lead to large generation deficit as wind energy penetration level increases. This paper investigates the enhancement of the fault ride through capability of the WG with the help of a Unified Power Quality Conditioner (UPQC). In particular, the relationship between the severity of the voltage sag and the rating requirements of the UPQC with respect to the installed wind generation is investigated. The study is found to be useful in retrofitting the existing installed fixed speed wind generators (FSIG), which lack the adequate system fault ride through capability on their own. The study also provides a guideline of choosing the rating of UPQC in accordance to the demanded level of fault-ride-through capability.

\section{Analysis of Voltage Ride-Through}

The system under consideration consists of a FSIG which is driven by a wind turbine and is supplying power to a utility network, as shown in Figure 1. The occurrence of a fault in the network will cause a voltage sag at the intermediate bus (M), restricting the ability of the generator to maintain the pre-disturbance power flow and possibly causing a trip of its protection system. When a disturbance or fault occurs in a power system, the terminal voltage of the wind turbine drops significantly, causing the electromagnetic torque and the electric power output of the generator to be greatly reduced. Since mechanical input to the system remains almost constant through the duration of fault, the wind-turbine starts to accelerate. As slip of the generator increases, reactive power absorbed from the connecting power system also increases considerably. Therefore it is not possible to bring back the generator terminal voltage to its pre-fault value unless over speeding of the generator is prevented. This triggers protection circuit to disconnect the wind turbine from the network $[2,3]$.

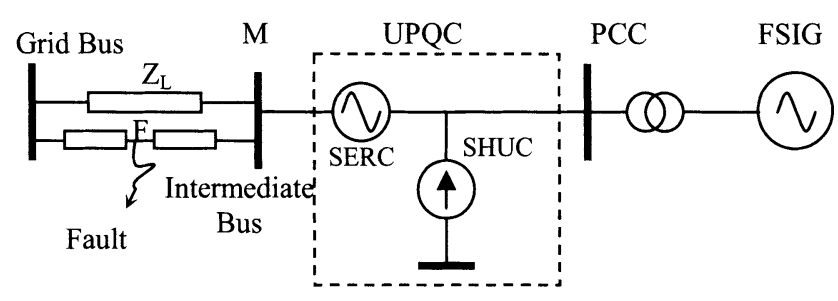

Figure 1: Model Configuration

\subsection{Induction Machine Model}

A FSIG model is considered in this paper which is driven by a 2 MW wind turbine. Machine parameters are provided in Appendix A and is based on system investigated in [4]. The asynchronous machine block which can operate either in motor or generator mode depending on the mechanical torque convention, provided in MATLAB/Simulink power system toolbox is used here. 


\subsection{Network Model}

A double circuit power system network with $\mathrm{X} / \mathrm{R}$ ratio of 5 is considered here as shown in Figure 1. It is a weak network with a fault level of 16 MVA. For the purpose of this paper, a three phase balanced fault is considered at the midpoint of one of the lines at location $\mathrm{F}$ as shown in Figure 1. The network is modelled with standard blocks available in power system toolbox of MATLAB/Simulink.

\subsection{UPQC Model}

The UPQC is combination of a shunt (SHUC) and a series (SERC) compensator connected together via a common DC link capacitor, which facilitates the sharing of active power. Each compensator consists of an IGBT based full bridge inverter, which can be operated in current or voltage controlled mode. In the absence of a significant energy storage element, the net active power consumption of the UPQC is zero. In this work, the series compensator (SERC) is represented as a controlled voltage source and the shunt compensator (SHUC) is represented as controlled current source as shown in Figure 2. The representation deals with fundamental components of voltage and current only.

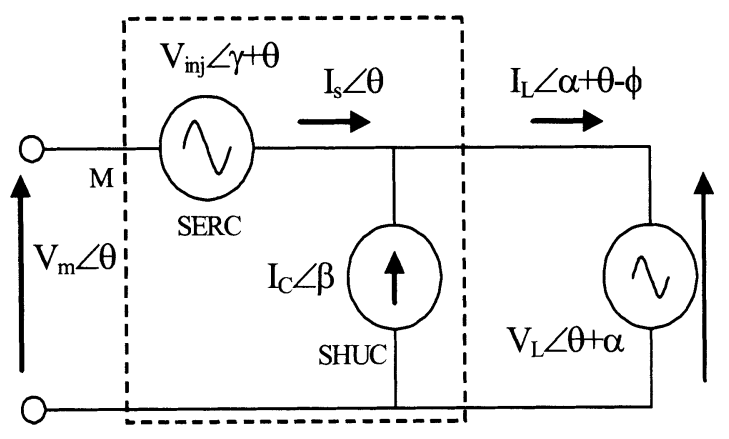

Figure 2: Fundamental Frequency Model of UPQC

In Figure 2, $V_{M}$ is the intermediate bus voltage which is taken as reference. $V_{L}$ is the voltage at the Point of Common Coupling (PCC). $V_{i n j}$ is the injected voltage from SERC of UPQC to compensate for any sag/swell occurring at PCC which is in phase with $V_{L}$. The relation among PCC voltage $\left(V_{L}\right)$, intermediate bus voltage $\left(V_{M}\right)$ and SERC voltage $\left(V_{i n j}\right)$ is given by:

$V_{L} \angle \theta+\alpha=V_{M} \angle \theta+V_{i n j} \angle \theta+\gamma$

$I_{L}$ is generator current and $I_{S}$ is the active component of current which flows from the generator to the grid. $I_{C}$ is the SHUC current. The relation among SHUC current $\left(I_{C}\right)$, generator current $\left(I_{L}\right)$ and current flowing to grid $\left(I_{S}\right)$ is given by:

$$
I_{L} \angle \theta+\alpha-\phi=I_{S} \angle \theta+I_{C} \angle \beta
$$

The angle $\varphi$ represents the phase angle of generator current $\left(I_{L}\right)$ with respect to PCC voltage $\left(V_{L}\right)$.
The phasor representation of the system during normal operating conditions is shown in by Figure 3 [5]. As there is no reactive power flow from the grid to the generator, the grid current $I_{S I}$ represents the active component of current which is in anti-phase with the PCC voltage $V_{L l}$. The SHUC current $I_{C l}$ is in quadrature with $V_{L I}$. If the intermediate bus voltage $V_{M}$ is taken as reference, the relationships between the UPQC voltages and currents are as follows:

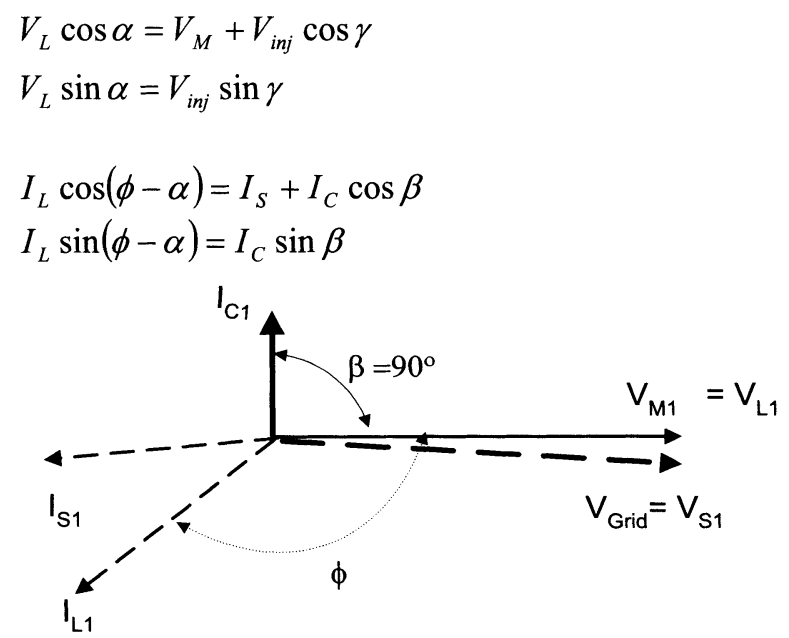

During the fault, the UPQC acts to restore the voltage at the PCC to the pre-disturbance level and maintains power flow from the machine to the grid at a constant level. This is achieved by injecting a compensating voltage (through the SERC). At the same time, active power balance has to be maintained between the SHUC and the SERC. Thus SHUC current will change to ensure that the net active power consumption of the UPQC is zero and the voltage at the PCC is constant. The phasor diagram during the fault condition is represented in Figure 4 [5].

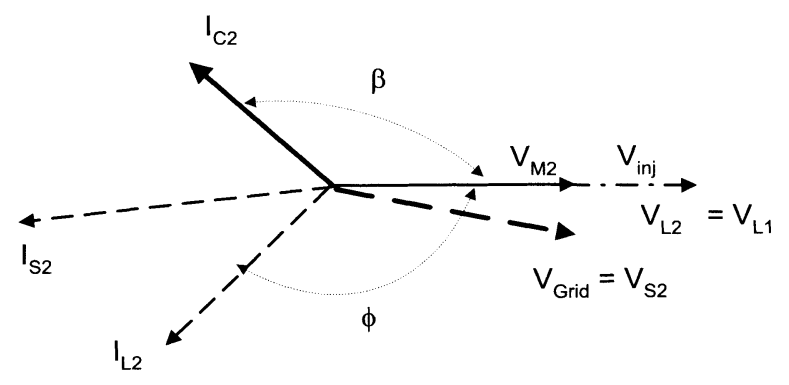

Figure 4: Phasor Diagram of UPQC during Fault

The value of $I_{C 2}$ depends on the reactive power requirement of the FSIG and the sag level at the PCC to be compensated. $I_{C 2}$ is the maximum current handled by the SHUC. Thus the VA rating of the SHUC can be given as:

$V A_{S H U C}=I_{C 2} V_{L 2}$ 
The value of $V_{i n j}$ depends on the desired level of the voltage compensation provided. The value of $I_{S 2}$ depends on the level of sag faced by the M bus. $I_{S 2}$ is the maximum current handled by the SERC. Thus the VA rating of the SERC is given by

$$
V A_{S E R C}=I_{S 2} V_{i n j}
$$

The VA rating of the UPQC is the combination of VA rating of the SHUC and the SERC.

\subsection{Simulation Approach}

The system described in Figure 1 is investigated by means of a simulation model in Simulink. The network, the UPQC and the FSIG, together with their appropriate controls, are represented in the simulation model. The complete system behaviour was investigated during the three phase balanced fault.

\section{Results}

To evaluate the enhanced fault-ride-through capability of the wind-generator (WG) with the help of UPQC, two sets of experiments have been simulated. Faults of different severity were created by choosing different values of fault impedance at point F. Some typical case studies are discussed in the following section.

\subsection{Simulation without UPQC}

The three phase fault occurs at $15 \mathrm{sec}$ and lasts for $500 \mathrm{~ms}$. Figure 5 shows the voltage at the PCC and the FSIG speed. A $45 \%$ sag is created at PCC due to a three-phase fault at point F. The FSIG accelerates and goes unstable due to mismatch in electrical and mechanical torque, which can be well observed here. The terminal voltage at the PCC does not return to its pre-fault value even after the clearance of the fault. Ultimately the over-speed relay and under-voltage relay operate to disconnect the FSIG from the network. The machine obviously lacks fault ride through capability.
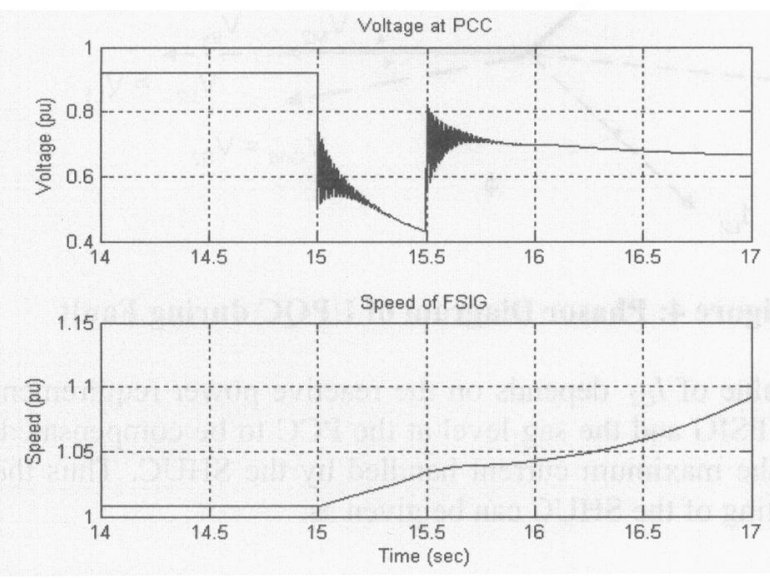

Figure 5: Voltage at PCC and FSIG Speed during Fault
The high reactive power demand of the machine and reduced active power flow from the machine can be seen in Figure 6.
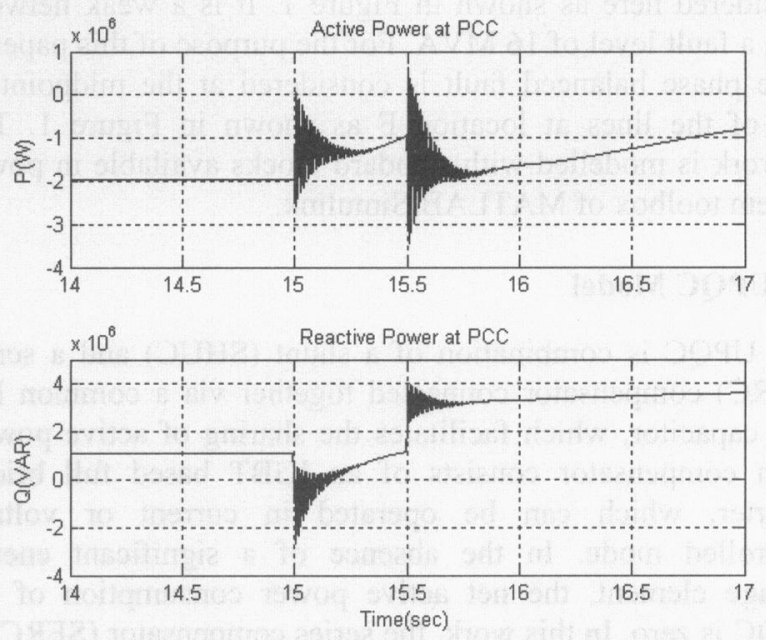

Figure 6: Active and Reactive Power at the PCC

\subsection{Simulation with UPQC}

The situation discussed above is considered again but in this case a UPQC is connected to the network at $1 \mathrm{sec}$ as shown in Figure 1. UPQC meets the reactive power requirement of the FSIG under normal operating condition. Thus there is no reactive power flow from the grid to the FSIG. Additionally the PCC voltage is also boosted, as compared to the situation described in Figure 5. A similar balanced fault is created at 2.5 second which lasts for $4 \mathrm{sec}$. The additional duration of fault has been chosen to ensure the stable operation of the FSIG during the fault.

The response of the FSIG with the UPQC operating can be observed in Figure 7 and Figure 8. It is found from Figure 7 that the SERC helps to restore the PCC voltage from $45 \%$ sag. During the transient period the fluctuation of speed is around $1 \%$, which is acceptable. The role of the UPQC in enhancing the fault ride through capability of the FSIG can be well appreciated with these results.
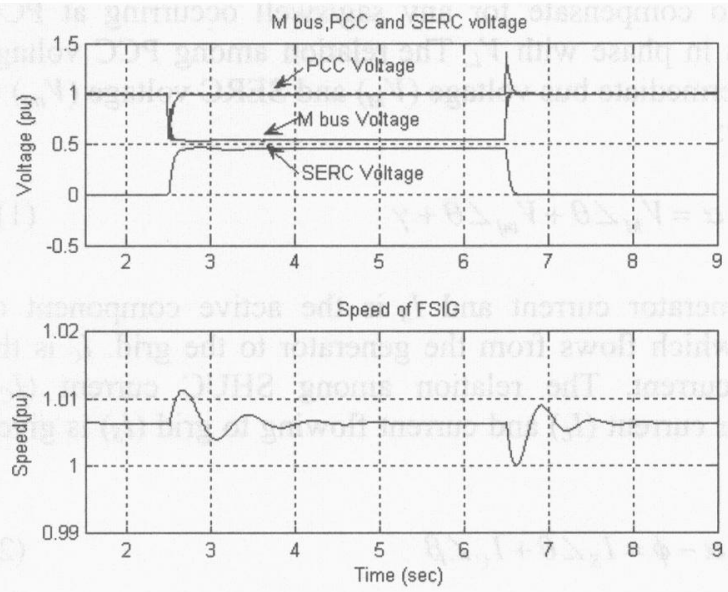

Figure 7: Voltage at $\mathrm{PCC}$ and Generator Speed with UPQC in operation 
The real power flow from the FSIG towards the grid is maintained constant throughout the fault duration. The power required by the SERC to maintain the PCC voltage to its nominal value is provided by the SHUC, and is transferred through the common dc link between them. Therefore during fault, the SHUC is required to carry additional current and is shown in Figure 9.
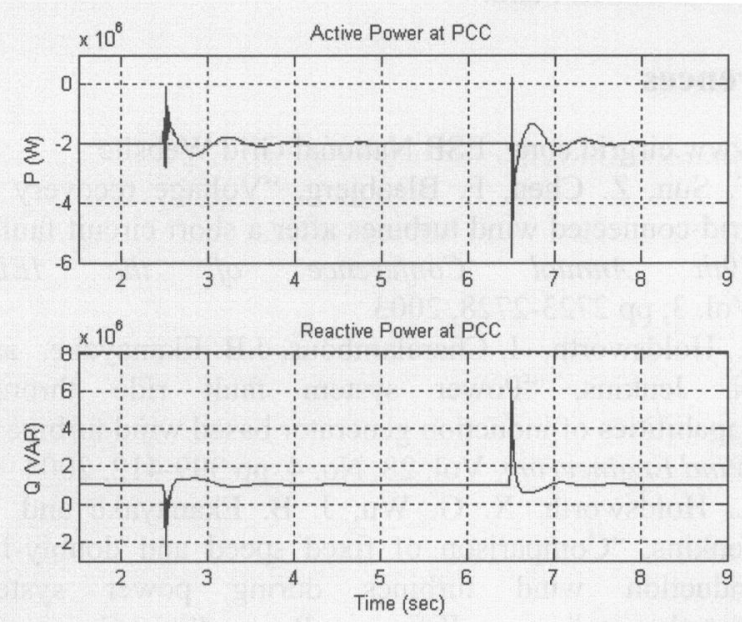

Figure 8: Active and Reactive Power at PCC with UPQC in operation

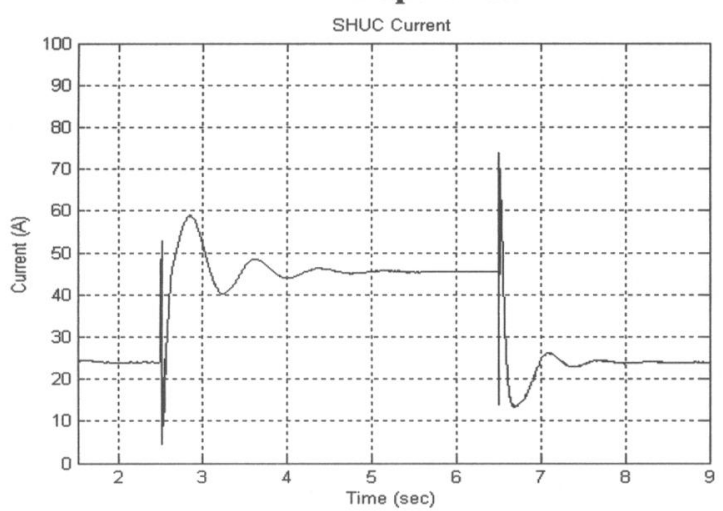

Figure 9: The SHUC current during Three Phase Fault
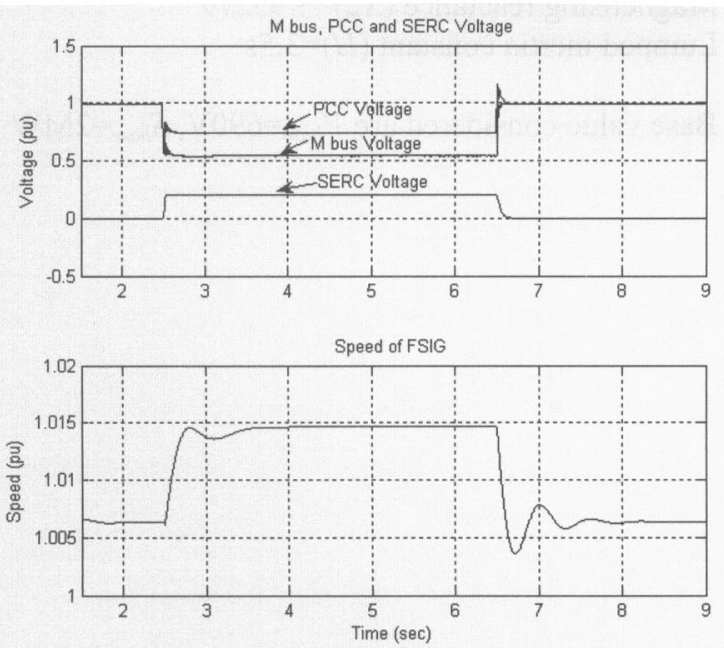

Figure 10: The voltage at the intermediate bus $(M)$ and at the PCC, with $20 \%$ Compensation from the SERC of UPQC
It is to be noted that the capability of the WG to withstand the occurrence of a fault depends on maintaining the voltage at the point of common coupling (PCC) at a level such that power flow from the generator can be sustained, and the reactive power demand is met. It has been observed that with the fault in the study considered, if the PCC voltage is retained up to $75 \%$ of its nominal value, though the WG starts to accelerate, it settles to a higher speed of around 1.015 p.u. with double reactive current demand as shown in Figure 10.
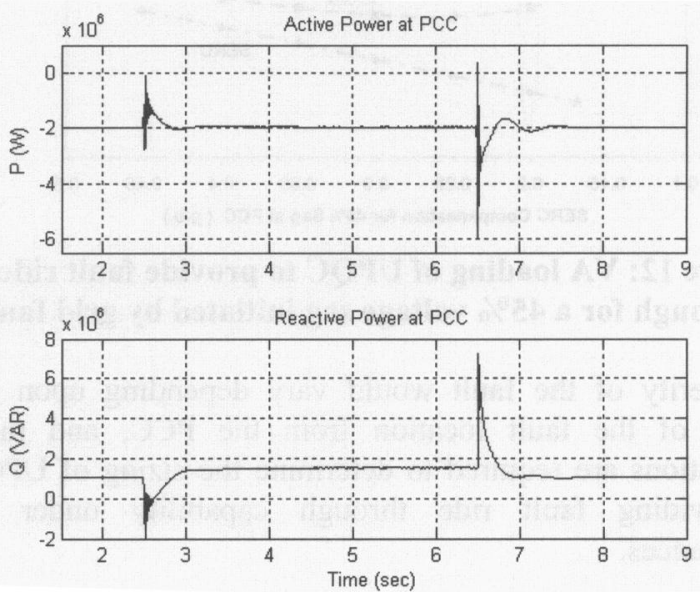

Figure 11: Active and Reactive Power at PCC with 75\% voltage restoration

Figure 11 shows that active power flow from the generator terminals is maintained constant through out the fault period and also after the fault is cleared. Reactive power demand of the machine increases by $50 \%$ during the fault period since the terminal voltage of the machine is $75 \%$ of its pre-fault value. The increased reactive power demand of the FSIG is met by the SHUC.

\subsection{Investigation of Capacity Requirements of UPQC}

To determine a suitable rating of UPQC for the installed WG capacity, various case studies were performed. It has been found that to restore the PCC voltage to $100 \%$, with the help of UPQC, the loading on the SERC is 1.66 MVA and the loading on the SHUC is 1.95 MVA. However, it is interesting to note that (as evident from Figure 10 and Figure 12) with only $20 \%$ compensation from the SERC, if the PCC voltage is restored to $75 \%$ of its nominal value, then with an increase of $1.4 \%$ speed in the FSIG, the generator achieves fault-ride-through capability and can come back to its normal operating point after the fault is cleared. A plot of different levels of voltage compensation from the SERC for the simulation model described above is presented in Figure 12. As there is a dependency on the rating between the SERC and the SHUC, it has been found that the minimum rating of the UPQC yields the individual optimum size of the SERC and the SHUC for providing successful voltage-ride-through for the most practical cases considered in this study. Therefore the SERC and the SHUC rating could be only 0.73 MVA and 
1.69 MVA respectively. This insight would reduce the sizes of SERC and SHUC rating by $56 \%$ and $13 \%$ respectively. The rating of the SHUC could be further reduced by the installation of switched capacitance.

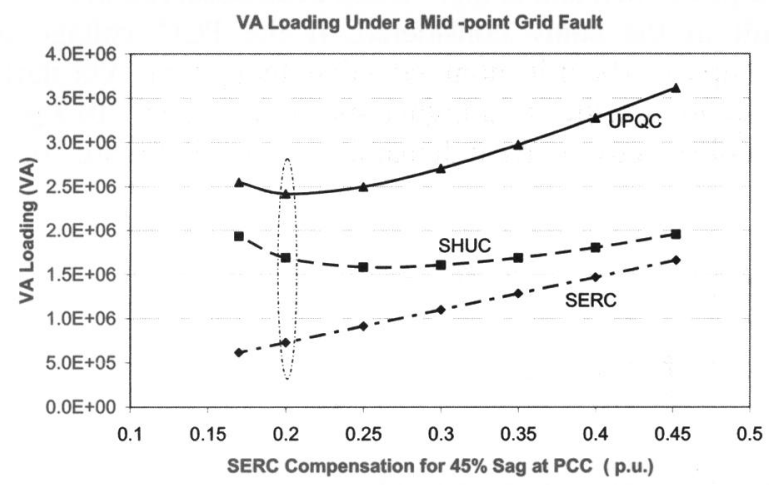

Figure 12: VA loading of UPQC to provide fault ride through for a $\mathbf{4 5 \%}$ voltage sag initiated by grid fault

The severity of the fault would vary depending upon the distance of the fault location from the PCC, and more investigations are required to determine the sizing of UPQC for providing fault ride through capability under all circumstances.

\section{Conclusions}

This simulation study has demonstrated the application of a UPQC device to the problem of voltage ride-through of a FSIG. The mechanism by which the UPQC sustains the power flow from the generator to the grid is shown. The response of the FSIG and the UPQC for full compensation is presented. The response of the system is also presented for partial series voltage compensation where the SERC is limited to $20 \%$ of the unconstrained value. In this case, ridethrough capability is again preserved. This approach allows for a detailed study of the UPQC requirement to ensure ridethrough capability for a specified level of voltage sag.

Clearly, the significant factors which affect the ride through capability of a UPQC/FSIG include the characteristics and rating of the generation capacity, the location of the fault and hence the severity of the voltage sag, the duration of the voltage sag and the rating and control strategy of the UPQC.
Further work will investigate the interdependence of these factors.

\section{Acknowledgements}

The authors would like to acknowledge the support provided by Enterprise Ireland under the Technology Commercialisation Fund.

\section{References}

[1.] www.eirgrid.com , ESB National Grid Website

[2.] T. Sun, Z. Chen, F. Blaabjerg, "Voltage recovery of grid-connected wind turbines after a short circuit fault", 29th Annual Conference of the IEEE Vol. 3, pp 2723-2728, 2003

[3.] L. Holdsworth, I. Charalambous, J.B. Ekanayake, and N. Jenkins, "Power system fault ride through capabilities of induction generator based wind turbines", Wind Engineering, Vol. 28, No. 4, pp 399-412, 2004

[4.] L. Holdsworth, X. G. Wu, J. B. Ekanayake and N. Jenkins, "Comparison of fixed speed and doubly-fed induction wind turbines during power system disturbances", IEE Proceedings-Generation Transmission and Distribution, Vol. 150, No. 3, pp 343-352, May 2003.

[5.] M. Basu, N. G. Jayanti, K. Gaughan, M. F. Conlon, "Application of a Unified Power Quality Conditioner (UPQC) to the enhancement of the fault ride-through capability of wind generation", $40^{\text {th }}$ University Power Engineering Conference (UPEC), 2005

\section{Appendix A}

\section{FSIG parameters (in pu)}

Stator resistance $\left(R_{S}\right)=0.00488$

Rotor resistance $\left(R_{r}\right)=0.00549$

Stator reactance $\left(X_{l s}\right)=0.09241$

Rotor reactance $\left(X_{l r}\right)=0.09955$

Magnetising reactance $\left(X_{m}\right)=3.95279$

Lumped inertia constant $(H)=3.5 \mathrm{~s}$

Base value considered are $V_{\text {base }}=690 \mathrm{~V}, S_{\text {base }}=2 \mathrm{MW}$ 